\title{
A normalização da pobreza e a questão liberal em Michel Foucault: o problema da população e o caráter utilitário das políticas sociais na modernidade
}

\author{
The normalization of poverty and the liberal issue in Michel Foucault: the \\ problem of the population and the utilitarian character of social policies in \\ modern times
}

\author{
Diego Arthur Lima Pinheiro \\ Universidade Estadual de Feira de Santana
}

\section{RESUMO:}

Este artigo apresenta um estudo das relações de poder que, historicamente, têm depauperado os modos de vida de todo um grupo populacional. Para tal, partimos da generalização do pauperismo que ocorreu na Europa Ocidental até o final do século XVIII, constituindo de maneira inédita uma população atrelada à vida nas ruas, a qual se buscará administrar por meio de novos mecanismos de governo. Os métodos para gerir a acumulação dos homens permitiram uma decolagem política em relação a formas de poder tradicionais que, interpeladas pelo liberalismo, cederam lugar para o utilitarismo como tecnologia de governo em meio às políticas sociais.

Palavras-chave: mecanismos de governo; genealogia da pobreza; liberalismo.

\section{ABSTRACT:}

This article presents a study of power relations that have historically depleted the livelihoods of an entire population group. For this, we start from the generalization of the pauperism that occurred in Western Europe until the end of the eighteenth century, constituting in an unprecedented way a population linked to life on the streets, which will seek to administer through new mechanisms of government. The methods for managing the accumulation of men allowed for a political takeoff in relation to traditional forms of power which, interpellated by liberalism, gave way to utilitarianism as a technology of government in the midst of social politics.

Key-words: mechanisms of government; genealogy of poverty; liberalism.

DOI: $10.12957 /$ mnemosine.2020.57669

Atento às transformações radicais de práticas políticas e econômicas que se instalaram nas sociedades ocidentais por volta do século XV, este artigo tem por objetivo evidenciar um conjunto de práticas dispersas, porém bem delimitadas, que tiverem como correlato a produção de uma população forjada sob o signo da miséria e que passará a fazer das ruas 
espaço de moradia e sustento. Neste texto, partimos mais especificamente da generalização do pauperismo que se deu na Europa Ocidental até o final do século XVIII, constituindo de maneira inédita uma população atrelada à vida nas ruas, a qual se buscará administrar por meio de novos mecanismos de governo.

Se a decolagem econômica do Ocidente começou com processos que permitiram a acumulação do capital, pode-se dizer também que os métodos para gerir a acumulação dos homens nos meios sociais permitiram uma decolagem política em relação a formas de poder tradicionais e que, logo caídas em desuso, foram substituídas por uma tecnologia minuciosa e calculada de sujeição. Como veremos, assim como seus contemporâneos, Jeremy Bentham se deparou com o problema do acúmulo dos homens. Porém, enquanto os mercantilistas apresentam o problema em termos de riqueza-pobreza, Bentham ousa colocar a questão em termos de poder: a população como alvo de relações específicas de governo.

Com efeito, se as disciplinas procuram individualizar os homens para satisfazer a uma exigência produtiva que deseja que cada um esteja em seu lugar, no local que lhe é próprio, dentro de uma cadeia que é a linha de produção (FOUCAULT, 2012b); se elas constroem indivíduos para alimentar a força de trabalho industrial, não se pode negar, no entanto, que a própria noção de força de trabalho apresenta mais o aspecto de um conjunto massificado do que o aspecto de um ajuntamento de individualidades agenciados segundo as necessidades do capital (REVEL, 2011:117). É neste sentido que em Segurança, território, população, Foucault irá destacar junto às técnicas disciplinares um conjunto paralelo de dispositivos que consiste em determinar conjuntos homogêneos de seres humanos e em lhes destinar uma economia específica dos poderes. Esses conjuntos dizem respeito àquilo que Foucault chama de populações.

As transformações das práticas políticas e econômicas que caracterizam a passagem do século XVII para o século XVIII alteram fundamentalmente o que se considerava até então como as formas do coletivo e, por esse motivo, tornam necessárias outras estratégias do poder. Para os mercantilistas do século XVII, a população aparece no princípio de uma dinâmica do poder do Estado e do soberano. Nesse sentido, a população é um elemento fundamental na dinâmica do poder porque garante, no interior do próprio Estado, toda uma concorrência da mão-de-obra possível, o que, consequentemente, assegura salários baixos pelas mercadorias produzidas e possibilidade de exportação, donde nova garantia do poder, novo princípio para o próprio poder de Estado (FOUCAULT, 2018b). 
No entanto, para que a população esteja assim na base tanto da riqueza como do poderio de Estado, é necessário que ela seja enquadrada por todo um aparato regulamentar que vai impedir a emigração, atrair imigrantes, beneficiar a natalidade. Em suma,_toda uma tecnologia de poder que vai fazer dessa população, considerada aqui como fonte de riqueza e de poder, uma força produtiva que trabalhará como convier, onde e em que convier. Dessa maneira, destaca Foucault (2018b: 94), a população só será concebida como força produtiva sob a condição de que ela seja efetivamente adestrada, repartida, decomposta, distribuída e fixada de acordo com os mecanismos disciplinares.

Não obstante, é importante notar que as coisas começam a mudar a partir do século XVIII. Enquanto uns consideravam que a população, por ser fonte de riqueza e de poder, deveria ser o máximo possível aumentada, os fisiocratas têm outra maneira de tratar a população. Os mercantilistas, ao falarem dessa população que por um lado era fundamento da riqueza e, de outro lado, deveria ser enquadrada por um sistema disciplinar, ainda a consideravam apenas como a coleção dos súditos de um soberano. Nesse sentido, com relação aos súditos, poder-se-ia impor de cima, de uma maneira inteiramente voluntarista, certo número de leis, de regulamentos que lhes diziam o que deviam fazer, onde deviam fazer e como deviam fazer.

Segundo Foucault (2018b: 94), com os fisiocratas e, de maneira geral, com os economistas do século XVIII, a população deixa de aparecer como uma coleção de súditos submetidos à vontade do soberano por intermédio de regulamentos, leis e decretos. A população passa a ser considerada com um conjunto de processos que é preciso administrar no que têm de natural e a partir do que têm de natural. Como podemos entender essa naturalidade da população? Nesse sentido, observamos junto com Foucault (2018b) que, primeiramente, a população, tal como é problematizada na prática governamental do século XVIII, não é mais a simples soma dos indivíduos que habitam um território. Tampouco é essa espécie de dado primeiro, de matéria sobre a qual vai se exercer diretamente a ação do soberano. De maneira inédita, a população aparece aqui na dependência de toda uma série de variáveis. Isto é, a população é um conjunto de processos que varia com o clima, varia com o entorno material, com a intensidade do comércio e da atividade de circulação das riquezas; varia, é claro, de acordo com as leis a que é submetida, os impostos, a maneira com que os direitos são assegurados; varia com os valores morais ou religiosos que são reconhecidos a este ou aquele tipo de conduta. 
É neste sentido, portanto, que a população aparece como um fenômeno da natureza. Um fenômeno da natureza que não se pode modificar por decreto. De outro modo, a relação entre o soberano e a população não pode ser simplesmente da ordem da obediência ou da recusa da obediência. De fato, as variáveis de que depende a população fazem com que ela escape consideravelmente da ação direta e voluntarista do soberano na forma da lei. Se a natureza da população impossibilita que ela seja modificada por decreto, isto não quer dizer que a população seja de uma natureza inacessível e que não seja penetrável. Muito pelo contrário, diz Foucault (2018b: 95). É neste ponto que a análise dos fisiocratas e dos economistas se torna interessante, porque essa naturalidade que se nota no fato da população pode ser acessada por agentes e técnicas de transformação, contanto que esses agentes e essas técnicas sejam ao mesmo tempo esclarecidos, refletidos, analíticos e calculados.

Se se quiser favorecer a população ou conseguir que a população esteja numa relação justa com os recursos e as possibilidades de um Estado, é necessário agir sobre toda uma série de fatores, de elementos que estão aparentemente longe da própria população, de seu comportamento imediato. Em todo caso, é por esses fatores distantes, pelas variáveis com as quais dada população se mantém em relação de dependência, que vai efetivamente ser possível agir sobre a população. É, portanto, uma técnica totalmente diferente que se esboça aqui: não se trata de obter a obediência dos súditos em relação à vontade do soberano, mas de atuar sobre coisas aparentemente distantes da população [a distribuição dos alimentos, das ruas, do fluxo das águas, o controle das taxas de natalidade, de mortalidade, das endemias, da pobreza, etc.], mas que se sabe, por cálculo e análise, que podem efetivamente atuar sobre a ela (FOUCAULT, 2008b: 95).

É essa naturalidade penetrável e administrável da população que faz uma mutação importantíssima na organização e na racionalização dos métodos de poder. A emergência da população como fenômeno da natureza é, ao lado do engendramento do indivíduo e do corpo adestrável, o outro grande núcleo tecnológico em torno do qual os procedimentos políticos do Ocidente se transformam (FOUCAULT, 2012a).

É também neste momento que se inventa o que chamaremos neste texto, em contraste com o governo dos pobres por meio das técnicas disciplinares, um governo dos efeitos de pobreza que se produzem como variáveis e se expressam no corpo geral da população. Em suma, trata-se de uma nova racionalidade de governo que irá se haver não exatamente com o problema da conduta dos pobres, mas se encarregará majoritariamente de analisar, calcular e 
administrar os fenômenos de pobreza que caracterizam uma dada população. Vale ressaltar que, historicamente, não há uma sucessão dessas diferentes formas de governo, mas uma simultaneidade. O que muda de uma época a outra é o modo como essas formas distintas de exercício do poder se relacionam entre si e, no contexto desse jogo, qual dessas técnicas de governo cumpre uma função dominante.

\section{O governo da pobreza por meio dos efeitos de normalização}

Em História da Loucura, Michel Foucault (2014) assinala que as práticas de internamento atravessaram uma profunda crise no século XVIII, colocando em questão não só o papel da reclusão dos pobres e a sua eficácia na condução destes para o trabalho, mas também a própria existência da reclusão. Esta crise, que proveio de um horizonte econômico e social, tornou imperativo libertar os pobres - ao menos os pobres válidos ${ }^{1}$ - das casas de internação, deixando-os expostos e circularem livremente para serem utilizados segundo as novas disposições do mercado. A chamada libertação dos mendigos apareceu então como efeito da necessidade de tecnologias de governo desvinculadas da posição periférica e marginal das casas de internação, favorecendo a tendência de se implantarem novos dispositivos de controle nos setores mais centrais e mais produtivos das cidades.

O problema da livre circulação dos homens e das coisas está imediatamente ligado à integração das cidades aos mecanismos de poder. Circulação entendida no sentido bem amplo, como deslocamento, como troca, como contato, como forma de dispersão, como forma de distribuição; situação em que se produz o problema: como é que homens e coisas devem circular ou não circular?

É na medida em que as cidades podem ser definidas, de uma maneira ou de outra, pelas circulações que favorecem ou obstaculizam, que problemas econômicos e públicos serão colocados. Problemas de técnica de governo a que foi preciso responder com novos mecanismos de poder cuja forma será encontrada naquilo que Foucault (2008a) chamou de mecanismos de segurança. O que especifica essa série complementar de mecanismos de poder - paralela à produção de corpos dóceis pelas técnicas disciplinares - será o empenho governamental em dirigir a população por meio do estabelecimento de dispositivos de segurança.

O termo segurança é utilizado por Foucault em um sentido muito específico, que pode ser definido a partir de quatro elementos: o meio, a aleatoriedade, a população e a 
normalização. O meio é o conjunto de elementos naturais (como rios, colinas, a vegetação, a fauna, etc.) e artificiais (as aglomerações humanas, as disposições das ruas, das moradias, as condições de saneamento, a intensidade do mercado, etc.) e as interações que se produzem entre eles a partir da circulação de homens, animais e coisas (FOUCAULT, 2008b: 28). Os dispositivos de segurança se ocupam, em resumo, dos fenômenos de população, em série, de longa duração. Daí a importância que, no desenvolvimento desses dispositivos, teve o que o século XVIII denominava ciência da polícia, isto é, a estatística. Em outras palavras, na medida em que se trata de administrar esse conjunto de elementos e seus efeitos, os dispositivos de segurança devem funcionar tendo em conta a aleatoriedade dos acontecimentos futuros.

Tudo vai ser organizado por uma série de questões que serão do seguinte gênero: qual é a taxa de média de pobreza como elemento positivo $?^{2}$ Como se pode prever estatisticamente que haverá esta ou aquela quantidade de pobres válidos num momento dado, numa sociedade dada, numa cidade dada, na cidade, no campo, em determinada região da cidade, etc.? Em segundo lugar, há momentos, regiões, sistemas assistenciais tais que essa taxa média vai aumentar ou diminuir? As crises, a fome, as guerras, as punições rigorosas ou, ao contrário, as punições brandas vão modificar essas proporções? Essa miséria como riqueza virtual de que falam os mercantilistas, quanto custa à sociedade, que prejuízos produz, que perdas, que ganhos? A assistência a esses pobres custa quanto?

De maneira geral, a questão que se coloca será a de saber como manter a circulação de mão-de-obra, como manter a população de pobres válidos, dentro dos limites que sejam social e economicamente aceitáveis em torno de uma média que será considerada, digamos, ótima para um funcionamento social dado (FOUCAULT, 2008b). Os dispositivos de segurança vão inserir os fenômenos de população - em especial, para nós, os fenômenos de pobreza - numa série de acontecimentos prováveis. A partir disso, as reações do poder ante a aleatoriedade desses fenômenos serão inseridas num cálculo de custo. E, por fim, no lugar de instaurar uma divisão binária entre o permitido e o proibido, vai-se fixar de um lado uma média considerada ótima e, depois, estabelecer os limites do aceitável, além dos quais a coisa não deve ir. É, portanto, uma outra gestão da pobreza e uma outra distribuição dos mecanismos de poder que assim se esboça.

Diante do exposto, uma vez inseridos os fenômenos de pobreza nessa série de cálculos, o que se procura produzir com relação a eles, por meio dos dispositivos de 
segurança, são os chamados efeitos de normalização. A contemporaneidade dos mecanismos de segurança e dos mecanismos disciplinares leva Foucault a reformular as noções de norma e de normalização. Distinguimos, então, dois sentidos para a norma: o disciplinar e o securitário. Em Segurança, território, população, Foucault (2008b: 95) diferencia a tal ponto as formas da normalização, que esta acaba por designar não mais que o procedimento vigente nos dispositivos de segurança. Por outro lado, a referência à norma no âmbito das disciplinas passa a ser pensada por ele segundo a lógica da normação, e não da normalização, expressão reservada aos dispositivos de segurança.

No marco da normação disciplinar, a norma se postula em função de um modelo que é preciso realizar a todo custo: “(...) a operação da normalização disciplinar consiste em procurar tornar as pessoas, os gestos, os atos, conformes a esse modelo" (FOUCAULT, 2008b: 95). Deste ponto de vista, o normal é apenas aquilo que está conforme à norma, e o anormal, o que resiste a ela. A lógica das normas disciplinares se estabelece a partir de uma anterioridade da norma como modelo, sendo o normal entendido como realização comprovada desse modelo. De certo modo, é a essa anterioridade que Foucault se refere sob o nome de normação, caráter prescritivo da norma que se esfumaça na lógica normalizadora dos dispositivos de segurança. Diferentemente, sua operação não vai no sentido de uma norma fixada anteriormente à demarcação final do normal e do anormal, mas surge diretamente a partir de uma distribuição empírica dos casos numa população.

Isto implica duas consequências importantes nas técnicas de governo. Em primeiro lugar, a normalidade traçada pelos mecanismos de segurança não tem um sentido unitário, mas diferencial, o que, longe de contradizê-la, adensa sua lógica. Em outras palavras, para cada fenômeno há uma normalidade que é possível analisar segundo sua frequência estatística. Assim, pode-se falar de uma distribuição normal dos casos de miséria sem riqueza virtual ou dos custos de assistência devido a ela, mas essa mesma distribuição deve expor-se em função das idades, dos sexos, das profissões, das diferentes cidades, dos bairros, de cada rua. Para um mesmo fenômeno há todo um jogo de normalidades diferenciais por meio das quais "vai-se tentar chegar a uma análise mais fina, que permitirá de certo modo desmembrar as diferentes normalidades umas em relação às outras" (FOUCAULT, 2008b: 82).

Em segundo lugar, a normalização consiste então no estabelecimento de uma normalidade das normalidades, com a salvaguarda de que esta normalidade de um tipo superior não se deduz de uma norma postulada com anterioridade como um modelo. Pelo 
contrário, ela aparece a partir da análise de diferentes regimes de normalidade. A questão será, portanto, traçar uma curva geral desses casos e chegar assim a uma normalidade última, um efeito de normalização cuja elaboração se baseia neles. Em suma, a distinção entre as normas da disciplina e as normas da segurança pode ser formulada da seguinte maneira: nas disciplinas, partia-se de uma norma e em seu prolongamento era possível distinguir o normal e o anormal; na segurança, ao contrário, haverá uma identificação do normal e do anormal, haverá uma identificação das diferentes curvas de normalidade, e a operação de normalização consistirá em fazer essas diferentes distribuições de normalidade funcionarem umas em relação às outras e em fazer de sorte que as mais desfavoráveis se assimilem as que são mais favoráveis (FOUCAULT, 2008b: 82).

No deslocamento do governo dos pobres para mecanismos de governo mais amplos, que abarcam o primeiro, mas tomam agora a população como alvo privilegiado, a norma não é apenas aquilo que asseguraria um comportamento adequado mediante as técnicas da disciplina. Ela não é apenas o fator que engloba os pobres, os delinquentes, os trabalhadores em seus comportamentos individuais. Mais além, a norma fixa efeitos de normalização sobre o corpo global da população. A população aparece, assim, na sua complexidade, tanto como objeto, isto é, aquilo sobre o que e para o que são dirigidos os mecanismos para obter sobre ela certo efeito; quanto como sujeito, já que é a ela que se pede para se comportar deste ou daquele jeito. A normalização consiste no conjunto das técnicas destinadas a assegurar-se da vida de uma população. Se de um lado a normalização reforça a valorização da vida de uma população, de outro, ela fixa os seus limites pela criação de normalidade que difunde.

Como dissemos antes, com os dispositivos de segurança não se trata de adotar o ponto de vista nem do que está permitido nem do que é obrigatório, mas de tomar distância para captar o ponto em que as coisas se produzirão, sejam elas desejáveis ou não. A norma disciplinar, por definição, regulamenta tudo. Não deixa escapar nada. Seu princípio é que até as coisas mais ínfimas não devem ser deixadas entregues a si mesmas. A menor infração à norma disciplinar deve ser corrigida com tanto maior cuidado quanto menor ela for. Já na lógica da segurança, a norma comporta um laisser--faire. Não é que ela deixe fazer tudo, mas há um nível em que o laisser-faire é indispensável. Deixar as pessoas fazerem, as coisas passarem, as coisas andarem, garantir que a circulação da mão-de-obra se desenvolva e siga livre seu caminho, isto é, de acordo com as leis, os princípios e os mecanismos que são os da realidade mesma. É que essa liberdade, diz Foucault, ao mesmo tempo ideologia e técnica de 
governo, deve ser compreendida no interior das mutações e transformações das tecnologias de poder. De uma maneira mais precisa, a liberdade nada mais é do que o correlativo da implantação dos dispositivos de segurança. "Um dispositivo de segurança só poderá funcionar (...) justamente se lhe for dado certa coisa que é a liberdade" (FOUCAULT, 2008b: 64). É essa liberdade de circulação, no sentido lato do termo, que devemos entender como sendo um dos aspectos da implantação dos dispositivos de segurança.

\section{O liberalismo como nova arte de governo}

Foucault vislumbra, desta forma, certo jogo de controle e seguridade próprio ao governo das populações. Controle e segurança encontram na vida da população seu principal valor, mas também seu limite. O governo das populações, com efeito, exibe esse jogo securitário nos limites da vida de uma população. O controle que se exerce sobre ela só tem sentido enquanto se efetua tendo em vista a própria população, a fim de garantir a seguridade e a liberdade correlata a esses mecanismos. O liberalismo corresponde a esse novo jogo das tecnologias de poder estabelecidos para o governo de uma população.

Em outras palavras, a relação de individualização gerada pela disciplina se distingue da relação de homogeneização criada pelas normas de regulação da população. A disciplina individualiza, e nesse sentido não pode reconfigurar a forma global do corpo social, enquanto os mecanismos de segurança, ao atuarem visando a população, podem dirigir-se a esse corpo social em sua vasta extensão, pois o nível de pertinência para a ação do governo é a população com seus fenômenos e seus processos próprios. Nesse sentido, o liberalismo não pode se sentir senão convocado por esta nova economia das relações de poder, adquirindo uma consistência específica pelo fato de que seu regime de intervenção concerne, precisamente, à vida de uma população no jogo fundamental de suas liberdades.

Curiosamente, salienta Foucault (2008a), o que caracteriza essa nova arte de governar é muito mais o naturalismo do que uma liberdade jurídica reconhecida como tal aos indivíduos e aos grupos populacionais. Esse naturalismo aparece nitidamente na concepção que os fisiocratas têm do mercado, isto é, quando afirmam que há mecanismos espontâneos nos processos da economia e que todo governo os deve respeitar se não quiser induzir efeitos opostos, inversos mesmo, aos seus objetivos. O que os fisiocratas deduzem disso é que o governo tem de conhecer esses mecanismos econômicos em sua natureza íntima e complexa. Depois de conhecê-los, deve comprometer-se a respeitar esses mecanismos. O que implica 
que o governo deve munir sua política de um conhecimento preciso, contínuo e claro do que acontece nos circuitos econômicos, de modo que a limitação de seu poder não é dada pelo respeito a suposta liberdade dos indivíduos, mas simplesmente pela evidência de uma análise econômica que ele saberá respeitar. Ele se limitará pela evidência de mercado, não pela liberdade dos indivíduos/populações.

Se estamos falando de liberalismos a propósito dessa nova prática governamental, isso não quer dizer que se está passando de um governo que era autoritário para um que se torna mais tolerante, mais flexível. Não se deve pensar a liberdade como um universal, que apresentaria, através dos tempos, uma realização progressiva, ou variações quantitativas, ou amputações mais ou menos graves. A liberdade nunca é mais que - e já é muito - uma relação atual entre governantes e governados, uma relação em que a medida do 'pouco demais' de liberdade que existe é dada pelo 'mais ainda' de liberdade que é pedido (FOUCAULT, 2008a:86).

De modo que se Foucault utiliza a palavra liberal, é precisamente porque essa prática governamental não se contenta em respeitar esta ou aquela liberdade, garantir esta ou aquela liberdade. Mais profundamente, ela é consumidora de liberdade, e isso na medida em que só pode funcionar se existe certo número de liberdades: liberdade do mercado, liberdade do vendedor e do comprador, livre exercício do direito de propriedade, livre circulação de mãode-obra, liberdade de discussão e, eventualmente, liberdade de expressão. A nova razão governamental consome liberdade, ou seja, é obrigada a produzi-la e organizá-la. Ela vai se apresentar, portanto, como gestora da liberdade, não no sentido do imperativo "seja livre". Não é o "seja livre" que o liberalismo formula, mas o seguinte: vou produzir o necessário para tornar você livre. Vou fazer de tal modo que você tenha a liberdade de ser livre. Com a gestão e a organização das condições de liberdade, o que se instaura no cerne da prática liberal é uma relação problemática, sempre móvel entre a produção de liberdade e aquilo que, produzindo-a, pode vir a limitá-la e a destruí-la. É necessário, de um lado, produzir a liberdade, mas esse gesto implica que, de outro lado, se estabeleçam limitações, controles, coerções e obrigações.

O liberalismo entra assim na história da governamentalidade como uma nova arte de governar que aparece em meados do século XVIII. É neste momento que se poderá constatar uma transformação importante que irá, aos olhos de Foucault (2008a: 14), caracterizar o que poderíamos chamar de razão governamental moderna. Essa transformação consiste na instauração de um princípio de limitação da arte de governar intrínseca à própria prática 
governamental. Esse limite vai se estabelecer na própria esfera da prática governamental entre as operações que podem ser feitas e as que não podem ser feitas. Em outras palavras, entre as coisas a fazer e os meios a empregar para fazê-las, de um lado, e as coisas a não fazer de outro. Na medida em que a limitação não divide os súditos, mas sim as coisas a fazer, o governo dos homens é uma prática que não é imposta pelos que governam aos que são governados. É uma prática que fixa a definição e a posição respectiva dos governados e dos governantes uns diante dos outros e em relação aos outros por toda uma série de conflitos, de acordos, de discussões, de concessões recíprocas.

Em suma, como se pode ver, o produto característico dessa regulação interna da arte de governo será uma deflação da governamentalidade. Para Foucault (2008a, p.40), com efeito, se trata de uma "arte de governar o menos possível". E o que vai permitir essa transformação fundamental das práticas de governo será a economia política. Segundo entendemos, a economia política é uma espécie de reflexão geral sobre a organização, a distribuição e a possibilidade da autolimitação dos poderes. A economia política coloca em análise as próprias práticas governamentais, não as interrogando em termos de direito a fim de saber se são legítimas ou não, mas sim sobre os efeitos dessas práticas. A economia política não se pergunta o que é que autoriza um soberano a cobrar impostos, mas quando, como, em que circunstâncias se cobra um imposto. Quando se cobra determinado imposto nesse momento dado, de tal categoria de pessoas ou de tal categoria de mercadorias, o que vai acontecer? Pouco importa para ela ser esse direito legítimo ou não, o problema é saber quais efeitos ele tem e se esses efeitos são negativos (FOUCAULT, 2008a:21).

O que a economia política procura tornar inteligível por meio de seus cálculos é uma certa naturalidade própria da prática de governo. Há uma natureza própria dos objetos da ação governamental. A natureza não é, para a economia política, uma região reservada e originária sobre a qual o exercício do poder não deveria ter influência. Ao contrário, a natureza é algo que corre sob, através, no próprio exercício da governamentalidade. Se ela atropelar essa natureza, se não a levar em conta ou se for de encontro às leis estabelecidas por essa naturalidade própria dos objetos que ela manipula, vai haver imediatamente consequências negativas para ela mesma. Em outras palavras, vai haver sucesso ou fracasso, que agora compõem o critério para a ação governamental, e não mais a legitimidade ou a ilegitimidade.

É neste sentido que, para Foucault, a economia política pôde se apresentar como a forma primeira dessa nova arte de governo autolimitativa. O que vai fazer com que um 
governo atropele a naturalidade própria dos objetos que ele manipula e das operações que ele faz? No momento em que viola essas leis de natureza, o que está em questão é que o governo simplesmente as desconhece, ignora sua existência, ignora seus mecanismos, ignora seus efeitos. E o maior mal de um governo, o que faz que ele seja ruim, não é o soberano ser ruim, é ele ser ignorante. Com a economia política entramos numa era cujo princípio poderia ser o seguinte: um governo nunca sabe o bastante que corre o risco de governar demais, ou ainda, um governo nunca sabe ao certo como governar apenas o bastante.

Em suma, é pelo viés da economia política que a possibilidade de uma autolimitação emerge, isto é, que a ação governamental se limite em função da natureza do que ela faz e daquilo sobre o que ela age se torne uma questão para a arte de governo. Essa transformação da prática governamental encontra seu correlato no novo regime das normas que chamamos anteriormente de normalização. Governar o menos possível é, efetivamente, deixar que os fenômenos próprios de uma população se desenrolem por si mesmos. Essa nova governamentalidade implica o reconhecimento da naturalidade da população. Por isso, a nova razão governamental não se esforça para desmanchar os efeitos de normalização de determinados modos de vida de uma população. Vai, ao contrário, na direção do estabelecimento de normalidades, no sentido de sua completa efetuação.

Em Nascimento da Biopolítica, Foucault (2008a) destaca duas propostas apresentadas para o problema da autolimitação das práticas governamentais. Uma que Foucault chamará de via rousseauniana, e que consiste, em termos claros e simples, em partir dos direitos do homem para chegar à delimitação da governamentalidade, passando pela constituição do soberano. A grosso modo, é uma maneira de colocar, por uma espécie de reinício ideal da sociedade, do Estado, do soberano e do governo, o problema da legitimidade e da inacessibilidade dos diretos. Um procedimento que podemos dizer, portanto, retroativo.

A outra via de limitação das competências do governo advém da própria prática governamental, e procura analisá-la em função dos limites de fato que podem ser postos a essa governamentalidade. Limites de fato que podem vir da história, que podem vir da tradição, que podem vir de um estado de coisas historicamente determinado, mas também podem ser e devem ser os limites adequados a serem estabelecidos justamente em função dos objetivos da governamentalidade, dos objetos com que ela lida, dos recursos do país, sua população, sua economia, dentre outros fatores (FOUCAULT, 2008a:55). 
A esfera de competência do governo vai ser definida, agora, de acordo com essa segunda via, justamente a partir do que seria útil e inútil o governo fazer ou não fazer. A limitação das práticas de governo será definida pelas fronteiras da utilidade de uma intervenção governamental. O que implica colocar a um governo, a cada instante, questões como: é útil? É útil para quê? Dentro de quais limites é útil? A partir de que se torna útil? E a partir de que se torna nocivo? Foucault nos adverte que não se trata aqui de uma projeção, no plano político, de uma espécie de ideologia utilitarista. Ao contrário, trata-se de definir uma prática de governo, definir qual deve ser sua esfera de ação e defini-la em termos de utilidade. A partir disso, o utilitarismo aparece como algo bem diferente de uma ideologia. "O utilitarismo é uma tecnologia de governo", e vai designar a posição que consiste em colocar à governamentalidade em geral a questão da sua utilidade ou de sua não-utilidade (FOUCAULT, 2008a:56).

A linha de tendência que vai procurar limitar a ação do poder público em termos de utilidade governamental vai caracterizar não apenas a história do liberalismo europeu, mas também a história do poder público no Ocidente. E, por conseguinte, é esse problema da utilidade, da utilidade individual e coletiva, da utilidade de cada um e de todos, da utilidade dos indivíduos e da utilidade em geral que irá se tornar o grande critério de elaboração dos limites do poder público.

Entramos, a partir do início do século XIX, numa era em que o problema da utilidade abrange cada vez mais os problemas das práticas de governo e da esfera da vida coletiva. No cerne do utilitarismo como tecnologia de governo, vale dizer, está a noção de interesse como critério da utilidade. Dito de outro modo, essa razão governamental que tem por característica a busca do seu princípio de autolimitação, é uma razão que funciona com base no interesse. Esse interesse já não é o do Estado inteiramente referido a si mesmo e que visa tão-somente seu crescimento, sua riqueza, sua população, sua força. Agora, o interesse a cujo princípio a razão governamental deve obedecer corresponde a um jogo complexo entre interesses individuais e coletivos, entre a utilidade social e o benefício econômico, entre o equilíbrio do mercado e o regime do poder público.

É nesse sentido que se pode dizer que "o governo (...) é algo que manipula interesses" (FOUCAULT, 2008a: 61). Ou seja, os interesses são, no fundo, aquilo por intermédio do que o governo pode agir sobre todas as coisas que são, para ele, os indivíduos, os grupos populacionais, os atos, as palavras, as riquezas, os recursos, a propriedade, os direitos, as 
políticas sociais. É por isso que o governo já não precisa agir diretamente sobre as coisas e sobre as pessoas. Ele só pode agir, só está em razão para intervir na medida em que os interesses, os jogos de interesse, tornam determinado indivíduo ou determinada coisa, determinado bem ou determinada riqueza, ou determinado processo algo de certo interesse para os indivíduos, ou para o conjunto dos indivíduos, ou para os interesses de determinado indivíduo confrontados ao interesse de todos.

Em outras palavras, o governo já não lida com as coisas em si, ele lida com estes fenômenos que são os interesses ou aquilo por intermédio do que determinado indivíduo, determinada coisa, determinada riqueza, interessa aos outros indivíduos ou à coletividade. Se, à guisa de exemplo, inserirmos nessa equação o problema de como tornar útil os pobres, "a fina película fenomenal dos interesses (...) é, doravante, a única coisa sobre a qual a razão governamental pode agir" (FOUCAULT, 2008a: 63). E com isso, punir os pobres, enclausuralos, educá-los ou deixá-los circular pela cidade aparecem como situações que devem ser calculadas em função de um jogo de interesses arraigado nos interesses dos outros, do seu meio, da sociedade. Vemos então emergir a seguinte série de perguntas: interessa punir? Que interesse há em punir? Que forma a punição deve ter para que seja interessante para a sociedade? Interessa enclausurar ou deixar circular a mão-de-obra? Interessa educar? E educar como, até que ponto, e quanto vai custar?

Para Foucault, o governo em seu novo regime é, no fundo, uma coisa que já não tem de ser exercida sobre sujeitos e sobre coisas sujeitadas. "O governo vai se exercer agora sobre o que podemos chamar de uma república fenomenal dos interesses" (2008a: 63). A questão fundamental do liberalismo será: qual o valor de utilidade do governo e de todas as ações do governo numa sociedade em que é a troca que determina o verdadeiro valor das coisas?

\section{Da utilidade e do interesse das políticas sociais}

Se, como vimos até aqui, a governamentalidade liberal se define como uma arte de não governar demais e está animada por uma forma de autolimitação, o problema que o governo dos pobres coloca será precisamente o de seu lugar nessa governamentalidade. Tal governo, em particular, não estará afastado do princípio de autolimitação por um excesso de intervenção que comprometa a chamada governamentalidade liberal?

De forma alguma. Como vimos apontando, o liberalismo não é o que aceita a liberdade, mas uma arte de governo que se propõe a fabricá-la a cada instante, suscitá-la e 
produzi-la com, bem entendido, todo o conjunto de injunções e problemas de custo que essa fabricação levanta. É a formidável extensão dos procedimentos de controle, de pressão, de coerção que vão constituir como que a contrapartida e o contrapeso das liberdades. Neste sentido, o liberalismo também encontra nas disciplinas pontos de articulação. O célebre panóptico, que Jeremy Bentham apresentava como devendo ser o procedimento pelo qual seria possível vigiar a conduta os indivíduos no interior de determinadas instituições, também será apresentado por ele mais tarde como devendo ser a fórmula geral de um governo liberal porque, no fundo, o que o governo deve fazer é dar espaço a tudo o que pode ser a mecânica natural tanto dos comportamentos quanto da produção. Deve dar espaço a esses mecanismos e não deve ter sobre eles nenhuma outra forma de intervenção, ao menos em primeira instância, a não ser a da vigilância (FOUCAULT, 1979; 2008a).

É apenas quando o governo, limitado de início a sua função de vigilância, vir que alguma coisa não acontece como exige a mecânica geral dos comportamentos, das trocas, da vida econômica, que ele haverá de intervir. Qual vai ser então o princípio de cálculo dessa intervenção? Será o que chamamos anteriormente de segurança. São os cálculos e os mecanismos da normalização implícitos na lógica da segurança que permitirão à ação governamental exercer, no prolongamento do governo dos pobres, um governo dos efeitos de pobreza. Isto é, um governo dos pobres não apenas por técnicas que tomam por alvo seus corpos individualizados, mas sim pelo corpo aqui entendido como supranumerários (CASTEL, 1989), como população excedente, exército de reserva, população flutuante - em todo caso, respondendo diretamente à especificidade de errância social ao se apresentar enquanto fenômeno de população.

Qual é, portanto, a questão social que a governamentalidade liberal faz sua? O que poderia ser a política social e em que sentido ela se orienta? Diante dessas questões, Foucault (2008a: 272) examina o tema no marco contemporâneo do estabelecimento dos mecanismos de seguridade social. A política social definida na França e na Inglaterra, logo após a Segunda Guerra, se configurou a partir de dois problemas e um modelo. Foi para manter o pleno emprego e atenuar os efeitos da desvalorização da moeda que tornara ineficaz a poupança, a capitalização individual, que se considerou necessário instituir uma política de cobertura social de riscos. A técnica para alcançar esses dois objetivos era o modelo de guerra, ou seja, o modelo da solidariedade nacional. O que acontece com o indivíduo em termos de infortúnio deve sempre ser assumido em nome da solidariedade nacional pela coletividade inteira. 
As políticas sociais que emergiram desse modelo foram políticas de consumo coletivo, garantidas por uma redistribuição permanente da renda, redistribuição permanente e consumo coletivo que deviam se aplicar ao conjunto da população. No entanto, a questão que se coloca a partir do momento em que se estabeleceram esses objetivos e em que se escolheu esse modelo de funcionamento é a de saber se uma política como essa, que se apresenta como política social, não vai ser ao mesmo tempo uma política econômica.

O princípio então de autolimitação da ação governamental tropeça com a necessária elaboração de uma política social. Surge assim o problema: como fazer funcionar uma dissociação entre o econômico e o social? Como será possível operar esse deslocamento? No rastro dessas questões, Foucault destaca a resposta neoliberal tal como foi formulada, na França da década de 1970, pelo o ministro de finanças Giscard d'Estaing e seu assessor técnico Lionel Stoléru. Essa resposta apela para um princípio, a saber, o de que a economia é essencialmente um jogo entre parceiros, que a sociedade inteira deve ser permeada por esse jogo e que o Estado tem por função precípua definir as regras econômicas do jogo e garantir que sejam efetivamente aplicadas.

Quais são essas regras? Elas devem ser tais que o jogo econômico seja o mais ativo possível, que beneficie, por conseguinte o maior número de pessoas possível, com simplesmente - e é aqui que Foucault chama atenção para a superfície de contato sem interferência do econômico e do social - uma regra. Uma regra de certo modo suplementar e incondicional no jogo: a de que deve ser impossível que um dos parceiros do jogo econômico perca tudo e, por causa disso, não possa mais continuar a jogar (FOUCAULT, 2008a:278). Regra que não altera em nada o jogo, mas que impede que alguém fique total e definitivamente fora dele.

Nessa ideia de um jogo econômico, vale dizer, ninguém originalmente participa porque quer; por conseguinte cabe à sociedade e à regra imposta pelo Estado fazer com que ninguém seja excluído desse jogo no qual a pessoa se viu envolvida sem nunca ter desejado explicitamente participar dele. A dissociação do econômico e do social sob a forma desse jogo econômico com cláusula de salvaguarda compreende duas partes. A primeira é puramente econômica e diz respeito ao restabelecimento do jogo de mercado sem levar em conta a proteção dos indivíduos. E sem ter de fazer uma política econômica que tenha como objetivo a manutenção do emprego e do poder aquisitivo. A outra parte diz respeito à noção do imposto negativo. 
O imposto negativo é um benefício social criado para ser socialmente eficaz sem ser economicamente perturbador. O projeto do imposto negativo provém do neoliberalismo americano e afirma que, se se quer ter uma proteção social eficaz sem incidência econômica negativa, deve-se criar uma forma de subsídio que seria em espécie e proporcionaria recursos suplementares a quem, e somente a quem, a título definitivo ou provisório, não alcança determinado patamar. Trata-se da constituição de benefícios compensatórios. O imposto negativo é concebido de uma maneira sofisticada, na medida em que é projetado para fazer com que as pessoas não tomem esse subsídio suplementar como uma espécie de meio de vida - algo que as levaria a evitar procurar trabalho e assim deixar de participar do jogo econômico. Então, toda uma série de modulações, de gradações, faz com que, por meio do imposto negativo, o indivíduo tenha por um lado garantido certo nível de consumo, mas com motivações suficientes, ou melhor, com frustrações suficientes para que ainda tenha vontade de trabalhar e seja sempre preferível trabalhar a receber um benefício.

E o que visa atenuar o imposto negativo? "Os efeitos de pobreza, e apenas seus efeitos" (FOUCAULT, 2008a: 281). Em outras palavras, o imposto negativo não visa de forma alguma ser uma ação que teria por objetivo modificar esta ou aquela causa da pobreza. Não é no nível das determinações da pobreza que o imposto negativo agiria, mas simplesmente no nível de seus efeitos. A este respeito, Foucault cita Stoléru quando este escreve: "para alguns, a ajuda social deve ser motivada pelas causas da pobreza"; por conseguinte, aquilo que ela deve cobrir e a que deve se dirigir é a doença, é o acidente, é a inaptidão para o trabalho, é a impossibilidade de encontrar um emprego. Nessa perspectiva, que é a tradicional, não se pode atribuir uma assistência a alguém sem se perguntar por que esse alguém necessita dessa assistência e sem procurar, por conseguinte, modificar as razões pelas quais necessita dela. "Para outros", são eles os partidários do imposto negativo, "a ajuda social deve ser motivada unicamente pelos efeitos da pobreza: todo ser humano", diz Stoléru, "tem necessidades fundamentais e a sociedade deve ajudá-lo a satisfazê-las, quando ele não consegue por si só” (FOUCAULT, 2008a: 281).

Diante do exposto, pouco importa a distinção que a governamentalidade ocidental procurou estabelecer entre os bons e maus pobres, os que não trabalham voluntariamente e os que estão sem trabalho por razões involuntárias. O único problema é saber se, quaisquer que sejam as razões, ele está ou não acima ou abaixo de certo nível de renda. E, caso esteja abaixo, sem ter de fazer todas aquelas investigações burocráticas, policiais, inquisitórias, 
conceder-lhe um subsídio tal que o mecanismo pelo qual lhe é concedido o estimule a voltar ao nível do patamar e ele se sinta suficientemente motivado, ao receber assistência, para ter vontade de passar de novo acima do patamar. E mesmo se não tem vontade, não tem a menor importância, pois ele permanecerá assistido.

O segundo ponto que ensejamos destacar acerca do imposto negativo como tecnologia de governo é que ele se configura de uma maneira a evitar tudo o que poderia ter, no âmbito das políticas sociais, efeitos de redistribuição geral de renda. Isto é, a grosso modo, toda a forma de gestão da pobreza que se poderia colocar sob o signo de uma política socialista ou socializante (FOUCAULT, 2008a: 282). Em outras palavras, evitar uma política na qual se procurará atenuar os efeitos de pobreza relativa devida a uma diferença de renda entre os mais ricos e os mais pobres. A política social implicada pelo imposto negativo é o contrário de uma política socializante. Ou seja, a pobreza relativa não entra em absoluto nos objetivos de semelhante política social. O único problema é a pobreza "absoluta", isto é, aquele limiar abaixo do qual se considera que as pessoas não têm uma renda decente capaz de lhes proporcionar um consumo suficiente. Vale dizer que por pobreza absoluta não se deve entender uma espécie de limiar válido para toda a humanidade. Essa pobreza absoluta considerada pelo mecanismo de imposto negativo é relativa para cada sociedade, havendo sociedades para as quais o limiar de pobreza absoluta estará situado relativamente alto e outras sociedades globalmente pobres em que o limiar de pobre absoluta seria muito mais baixo. Logo, trata-se de um limiar relativo de pobreza absoluta (FOUCAULT, 2008a).

Introduz-se ainda por esse mecanismo uma espécie de clivagem inédita até este ponto no âmbito do governo da pobreza. As políticas sociais com tendências mais ou menos socializantes, desde o século XIX, haviam desejado fazer com que as intervenções econômicas fossem tais que não houvesse, no interior da população, a separação entre pobres e menos pobres. No entanto, ao fazer funcionar um governo dos efeitos de pobreza por meio da tecnologia do imposto negativo, temos aqui uma política social que vai definir certo limiar, um certo limiar absoluto para dada sociedade, que vai separar os pobres dos não-pobres, os assistidos dos não-assistidos. Haverá, portanto, uma gradação dos fenômenos de pobreza numa dada população e, por conseguinte, uma gradação da assistência que lhes será concedida, ou seja, uma gradação dos benefícios, dos direitos sociais, da acessibilidade aos serviços que terá por objetivo assegurar o mínimo necessário para manter dada população envolta nas tramas de um jogo econômico. 
O imposto negativo assegura, assim, um certo nível de seguridade social, mas por baixo, isto é, em todo o resto do campo social vai se deixar agir, precisamente, os mecanismos econômicos do jogo, os mecanismos de concorrência, os mecanismos de empresa e a lógica do empreendedorismo. Isso implica dizer que, acima do limiar, cada um deverá ser para si e para os outros uma empresa. Uma sociedade formalizada no modo da empresa e da expressão concorrencial vai ser possível acima do limiar, e ter-se-á simplesmente uma segurança-piso, isto é, a anulação de certo número de riscos a partir de certo patamar inferior (FOUCAULT, 2008a: 284). Em outras palavras, vai-se ter uma população que será, do lado do piso econômico, uma população em perpétua mobilidade entre níveis de assistência, que será concedida se um certo número de infortúnios se produzir de tal modo que ela desça abaixo do limiar. Ao mesmo tempo, essa mesma população será utilizada e utilizável, se as necessidades do jogo econômico a mobilizar, conforme as necessidades dos próprios mecanismos deste jogo. Vemos aparecer aqui uma população flutuante infra e supralimiar. População que constituirá, para uma economia que renunciou ao objetivo do pleno emprego, uma perpétua reserva de mão-de-obra que se poderá utilizar, se necessário, mas que também se poderá mandar de volta ao seu estatuto de assistida ou de descartáveis. Isso implica um fundo de população flutuante em que mecanismos de seguro permitem que cada um subsista de tal modo que poderá sempre ser candidato a um possível emprego, se as condições de mercado assim exigirem. Há, no entanto, uma importante diferença na produção da atual população flutuante que, para Foucault (2008a: 285), a distingue totalmente daquela pela qual o capitalismo industrial dos séculos XVIII e XIX se constituiu e desenvolveu, e que também podia se apresentar como uma perpétua reserva de mão-de-obra.

A partir do momento em que a população camponesa não será mais aquela a proporcionar, de maneira hegemônica, essa espécie de fundo perpétuo de reserva de mão-deobra, será necessário constituí-lo de outro jeito. Esse modo totalmente diferente será o da constituição de uma população urbana assistida, assistida de um modo bastante liberal, como vimos até aqui. Em suma, deixa-se às pessoas a possibilidade de trabalhar se quiserem ou se não quiserem. Proporciona-se, sobretudo, a possibilidade de não as fazer trabalhar, se não se tem o interesse de fazê-las trabalhar. Garante-se simplesmente a elas a possibilidade de existência num certo patamar, e é assim que poderá funcionar essa política social liberal assim concebida. Em resumo, o objetivo principal da política social liberal será tal que, construída a partir de jogos de interesse e utilidade, sem mexer no jogo econômico e deixando, por 
conseguinte, a sociedade se desenvolver como uma sociedade empresarial, instaurar um certo número de mecanismos de intervenção para assistir os que deles necessitam naquele momento, e somente naquele momento em que deles necessitam.

\section{Considerações finais}

Ao realizarmos uma leitura dos cursos Segurança, território, população (2018b) e Nascimento da Biopolítica (2018a), ambos ministrados por Michel Foucault no final da década de 1970, tomando por ênfase neste processo o aparecimento de uma população extremamente depauperada que irá se instalar nos centros urbanos, produzindo novos problemas de governo que, por sua, vez, demandarão a invenção tecnologias biopolítica inéditas, podemos encarar esses dois cursos como peças-chave na construção de uma história da pobreza e do governo dos pobres no contexto específico da modernidade europeia. Ao longo do caminho percorrido até aqui, vimos uma modalidade também bem particular de uma maquinaria mais geral desta possível história do governo dos pobres. Em outras palavras, um governo que se exerce por efeitos de normalização, isto é, por intervenções nas condições e modos de vida da população, em contraste com as tecnologias disciplinares que investem diretamente no corpo dos indivíduos - conforme analisado por Foucault em Vigiar e Punir (2012b). O caráter utilitário das políticas sociais em contexto europeu foi uma das formas de responder aos chamados problemas de população e problemas dos limites da ação governamental. Ao destacarmos estes elementos, ao perspectivarmos o trabalho com os cursos a partir do governo dos pobres, esperamos contribuir para os debates e pesquisas em torno de uma história da pobreza, entendida por nós como um fenômeno inédito em suas formas e proporções, e que teria surgido na Europa em fins do século XVIII. A pobreza, portanto, como uma invenção recente na história e o pauperismo generalizando, assim como a sua gestão, como efeitos de tecnologias biopolíticas operadas por um novo artefato do poder: o caráter utilitarista das políticas sociais no contexto analisado por Foucault.

Por fim, vale ressaltar que o estudo realizado e proposto sob a forma deste artigo não se pretende uma análise generalista e/ou universalista. Quando se trata de pensar processos históricos junto de Foucault, estamos sempre nos referindo a contextos precisos e recortes de tempo bem delimitados. É importante deixar explícito que nosso esforço neste texto não é o da transposição de uma realidade histórica para outra, a brasileira. Neste sentido, este artigo pode trazer algumas pistas, oferecer algumas contribuições que sirvam como disparadores 
para pensarmos e trabalharmos na investigação de nossos processos históricos, forjando as nossas próprias referências teórico-metodológicas ao logo do caminho. Algo que, felizmente, já vem acontecendo nas universidades brasileiras.

\section{Referências}

CASTEL, R. As metamorfoses da questão social: uma crônica do salário. Trad. Iraci D. Poleti,. Petrópolis: Vozes, 1998.

FOUCAULT, M. Nascimento da biopolítica: curso dado no Collège de France (1978-1979). Trad. Eduardo Brandão. São Paulo: Martins Fontes, 2008a.

FOUCAULT, M. Segurança, território, população: curso dado no Collège de France (19771978). Trad. Eduardo Brandão. São Paulo: Martins Fontes, 2008b.

FOUCAULT, M. Ditos e escritos: segurança, penalidade e prisão. Vol. VIII. Trad. Vera Lucia Avellar Ribeiro. Rio de Janeiro: Forense Universitária, 2012a.

FOUCAULT, M. Vigiar e punir: nascimento da prisão. Trad. Raquel Ramalhete. Petrópolis, RJ: Vozes, 2012b.

FOUCAULT, M. História da Loucura na Idade Clássica. Trad. José Teixeira Coelho. São Paulo: Perspectiva, 2014.

REVEL, J. Dicionário Foucault. Trad. Anderson Alexandre da Silva. Rio de Janeiro: Forense Universitária, 2011.

Diego Arthur Lima Pinheiro Professor da Área de Psicologia da Universidade Estadual de Feira de Santana E-mail: dalpinheiro@uefs.br

\footnotetext{
${ }^{1}$ Refiro-me aqui a uma nova fronteira, estabelecida em meados do século XVIII, que opera uma distinção dos pobres, separando-os entre pobres válidos e pobres inválidos. Aos pobres ditos inválidos, recairá a necessidade de instituições de cuidado específicas. A este respeito, Foucault destaca que ao lado das workhouses serão fundadas as poorhouses, que serão destinadas apenas àqueles que se tornaram "indigentes com a idade, por doença ou por enfermidade e que são incapazes de prover à própria subsistência pelo trabalho" (2014: 404). Quanto aos pobres tidos como válidos, não serão mais mandados nem para essas casas nem para as workhouses, mas se irá proporcionar-lhes, em seu lugar, um trabalho conveniente às suas forças e capacidade.

${ }^{2}$ A expressão pobreza como elemento positivo emerge, nos séculos XVII e XVIII, atrelada ao imperativo de utilizar os pobres, os chamados vagabundos, os exilados e emigrados de toda espécie como um dos segredos da riqueza virtual na concorrência entre as nações.
} 